\title{
Transformation of myelodysplastic syndrome with isolated $5 q$-syndrome to chronic myelogenous leukemia with a novel complex BCR/ABL1 translocation with rapid progression to blast crisis
}

\begin{abstract}
Ann-Leslie Zaslav ${ }^{1 *}$, Rajarsi Gupta ${ }^{1}$, Bruce T. Burks² ${ }^{2}$ Michael Schuster ${ }^{3}$, Bita Jalilizeinali³ , Erin Knorr ${ }^{1}$, Dan Tully ${ }^{1}$, Paula Fernicola ${ }^{1}$, Theresa Mercado', Silvia Spitzer', Marc Golightly', Yupo Ma' and Tahmeena Ahmed'
\end{abstract}

*Correspondence: ann-leslie.zaslav@stonybrookmedicine.edu

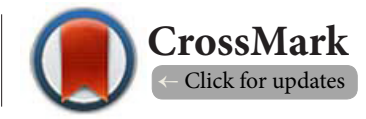

'Department of Pathology, Stony Brook University Medical Center, Stony Brook, NY, USA.

${ }^{2}$ Department of Pathology, St. Catherine of Siena Medical Center, Smithtown, NY, USA.

${ }^{3}$ Department of Medicine, Stony Brook University Medical Center, Stony Brook, NY, USA.

\begin{abstract}
We report a case of a 72 year old female who was referred to our institution in August 2010 for Myelodysplastic syndrome (MDS) with a deletion of part of the long arm of chromosome 5 [i.e., del(5) (q12q33)]. In June 2014, she transformed to Chronic Myelogenous Leukemia (CML), where cytogenetic and FISH analysis of the bone marrow $(\mathrm{BM})$ revealed the $\operatorname{del}(5 \mathrm{q})$ in $1.5 \%$ of nuclei and a complex BCR/ABL1 translocation [i.e., 45,XX,t(9;15;22)(q34;p10;q11.2),-22]. Six weeks later, in July 2014, she transformed to an Acute Myelogenous Leukemia (AML) blast crisis. RT-PCR was positive for BCR/ABL1 transcript. The patient was treated with a tyrosine kinase inhibitor, Nilotinib, then had a haploidentical allogeneic bone marrow transplant from her son, and was in remission after treatment. However, throughout the course of nine subsequent cytogenetic analyses, the patient continued to undergo clonal chromosome evolution, even during remission. Transformation from MDS del(5q) to CML with rapid progression to blast crisis has rarely been reported. To our knowledge, transformation with this complex translocation has never been described. Here we describe these rare cytogenetic findings and discuss possible mechanisms involved in the persistent and evolving clonal cytogenetic abnormalities seen during the clinical course of the disease.
\end{abstract}

Keywords: Chromosomal abnormality, complex BCR-ABL1 translocation, 5q-syndrome, clonal chromosomal evolution

\section{Introduction}

Myelodysplastic syndrome (MDS) is a group of clonal hematopoietic stem cell disorders that are characterized by peripheral blood cytopenias, dysplastic morphology, and clonal cytogenetic abnormalities. The majority of clonal cytogenetic abnormalities reported in $30 \%$ to $50 \%$ of MDS are monosomy 7 , loss of $Y$, del(5q), del(7q), del(20q) and trisomy 8 .

MDS with isolated $5 q$ - syndrome is characterized by anemia, with or without other cytopenias, and a deletion of part of the long arm of chromosome 5. Patients with MDS with 5qsyndrome have a good prognosis and are usually monitored without treatment $[\mathbf{1}, \mathbf{2}]$.
Multiple genetic abnormalities occur during the evolution of MDS. BCR/ABL1 rearrangements occur with a frequency of $1 \%$ (5). To our knowledge, this complex BCR/ABL1 translocation has never been reported. We present a case of MDS transforming to $C M L$ with a complex BCR/ABL1 translocation followed by rapid progression to an AML blast crisis.

\section{Case presentation}

A 72 year old female presented to an outside institution in 2007 and was diagnosed with MDS with isolated del(5q). Her care was transferred to our institution in August 2010, where $\mathrm{G}$-banded chromosome analysis of the bone marrow (BM) 
revealed a deletion of part of the long arm of chromosome 5 [i.e., del(5)(q12q33)] in 11/20 metaphase cells and was confirmed by FISH (Table 1). The complete blood count (CBC) of the peripheral blood showed anemia (Table 2).

In June 2014, she presented with worsening anemia, leukocytosis, and thrombocytosis (Table 2). Bone marrow evaluation showed a hypercellular marrow with left-shifted granulocytic and megakaryocytic hyperplasia, consistent with transformation of MDS to chronic phase Chronic Myelogenous Leukemia (CML). Cytogenetic and FISH analyses of the BM revealed del $(5 q)$ in $1.5 \%$ of nuclei and a complex BCR/ABL1 translocation [i.e., 45, XX,t(9;15;22)(q34;p10;q11.2),-22]. RT-PCR was positive for BCR/ABL1 transcript.

Seven weeks later, in July 2014, her CBC still showed anemia, leukocytosis, and thrombocytosis, but now there were $14 \%$ blasts in the peripheral blood and $18 \%$ blasts by flow cytometry of the BM. Her disease transformed from CML chronic phase into a myeloid blast crisis. This was a rare occurrence of rapid transformation from MDS to CML to blast crisis. The patient was treated with Nilotinib, a tyrosine kinase inhibitor. The patient had a haploidentical allogeneic bone marrow transplant from her son. After completing treatment, the patient was in morphologic remission, with normal marrow morphology and cellularity. However, she continued to undergo cytogenetic clonal chromosomal evolution (Figure 1 and Table 1).

To our knowledge, this is the first report of MDS transformation to CML followed by rapid progression to an AML blast crisis with this complex BCR/ABL1 translocation.

\section{Materials and methods}

Cytogenetic G-band metaphase analysis and fluorescence in situ hybridization (FISH) were performed using standard cytogenetic techniques on bone marrow (BM) and unstimulated

Table 1. Cytogenetic results.

\begin{tabular}{|c|c|c|c|c|}
\hline \multicolumn{2}{|c|}{ Analysis } & \multirow{2}{*}{$\begin{array}{l}\text { Specimen } \\
\text { Type }\end{array}$} & \multirow{2}{*}{$\begin{array}{l}\text { G banding } \\
\text { (number of cells in brackets) }\end{array}$} & \multirow{2}{*}{ FISH ${ }^{* * *}(\%+)$} \\
\hline *\# & Date & & & \\
\hline$\# 1$ & $08 / 05 / 10$ & ${ }^{*} \mathrm{BM}$ & $46, \mathrm{XX}, \operatorname{del}(5)(\mathrm{q} 12 \mathrm{q} 33)[11] / 46 \mathrm{XX}[8]$ & $\operatorname{del}(5)(\mathrm{q} 31) /(18.5 \%)$ \\
\hline$\# 2$ & $06 / 06 / 14$ & $* * * * U B$ & $45, \mathrm{XX}, \mathrm{t}(9 ; 15 ; 22)(\mathrm{q} 34 ; \mathrm{p} 10 ; \mathrm{q} 11.2),-22[20]$ & $\begin{array}{l}\operatorname{del}(5)(q 31) /(1.5 \%) \\
\text { BCR/ABL1 + (100\% metaphases })\end{array}$ \\
\hline \#3 & $07 / 11 / 14$ & UB & $\begin{array}{l}45, X X, t(9 ; 15 ; 22)(\mathrm{q} 34 ; \mathrm{p} 10 ; \mathrm{q} 11.2),-22[12] \\
/ 46, \mathrm{XX}, \mathrm{t}(9 ; 15 ; 22)(\mathrm{q} 34 ; \mathrm{p} 10 ; \mathrm{q} 11.2),+\operatorname{der}(15), \mathrm{t}(9 ; 22) \\
(\mathrm{q} 34 ; \mathrm{q} 11.2),-22[3]\end{array}$ & $\begin{array}{l}\text { BCR/ABL1 +/(93\%) } \\
\text { Extra BCR/ABL1+ (3\% metaphases) } \\
\text { extra der(15)t }(9 ; 15 ; 22)(\mathrm{q} 34 ; \text { p } 10 ; \mathrm{q} 11.2)(30 \% \\
\text { metaphases) }\end{array}$ \\
\hline$\# 4$ & $07 / 21 / 14$ & UB & $\begin{array}{l}45, \mathrm{XX}, \mathrm{t}(9 ; 15 ; 22)(\mathrm{q} 34 ; \mathrm{p} 10 ; \mathrm{q} 11.2),-22[15] \\
\text { /46,XX,t }(9 ; 15 ; 22)(\mathrm{q} 34 ; \mathrm{p} 10 ; \mathrm{q} 11.2) \\
+\operatorname{der}(15) \mathrm{t}(9 ; 15 ; 22)(\mathrm{q} 34 ; \mathrm{p} 10 ; \mathrm{q} 11.2),-22[5]\end{array}$ & $\begin{array}{l}\text { BCR/ABL } 1+100 \% \\
\text { Extra BCR/ABL } 1+/(5.5 \%) \\
{[\text { an extra der }(15) t(9 ; 15 ; 22)(\mathrm{q} 34 ; \mathrm{p} 10 ; \mathrm{q} 11.2)]} \\
\text { (10\% of metaphases) }\end{array}$ \\
\hline \#5 & $11 / 14 / 14$ & $\mathrm{BM}$ & $\begin{array}{l}45, \mathrm{XX}, \mathrm{t}(9 ; 15 ; 22)(\mathrm{q} 34 ; \mathrm{p} 10 ; \mathrm{q} 11.2),-22[6] \\
/ 46, \mathrm{XX}, \mathrm{t}(9 ; 15 ; 22)(\mathrm{q} 34 ; \mathrm{p} 10 ; \mathrm{q} 11.2),+\operatorname{der}(15) \\
\mathrm{t}(9 ; 15 ; 22)(\mathrm{q} 34 ; \mathrm{p} 10 ; \mathrm{q} 11.2),-22[1] \\
/ 46, \mathrm{XX}, \mathrm{t}(9 ; 15 ; 22)(\mathrm{q} 34 ; \mathrm{p} 10 ; \mathrm{q} 11.2) \\
\operatorname{der}(22) \mathrm{t}(9 ; 22)(\mathrm{q} 34 ; \mathrm{q} 11.2)[1] \\
/ 45, \mathrm{XX}, \operatorname{del}(5)(\mathrm{q} 12 \mathrm{q} 33)[1] \\
/ 46, X X[11]\end{array}$ & $\begin{array}{l}\operatorname{del}(5)(\mathrm{q} 31)(0.5 \%) \\
\mathrm{BCR} / \mathrm{ABL} 1+/(41 \% \text { metaphases })\end{array}$ \\
\hline \#6 & $4 / 24 / 15$ & UB & $\begin{array}{l}\text { No chromosomes } \\
\text { (no growth) }\end{array}$ & $\begin{array}{l}\operatorname{del}(5)(q 31)(0.5 \%) \\
3 \text { copies of } A B L 1(16 \%) \\
1 \text { copy BCR/ABL } 1 /(7.5 \%)\end{array}$ \\
\hline \#7 & $7 / 22 / 15$ & $\mathrm{BM}$ & $47, \mathrm{XX},+8[\mathrm{CP} 5] / 46, \mathrm{XX}[7]$ & $\begin{array}{l}+8(5 \%) \\
+9(6 \%) \\
\text { Normal BCR/ABL1 and } 5 q\end{array}$ \\
\hline$\# 8$ & $11 / 16 / 15$ & $\mathrm{BM}$ & $\begin{array}{l}\bullet 42 \sim 46, X X, \operatorname{der}(5) \mathrm{t}(5 ; ?)(\mathrm{p} 15 ; ?),-7,-9 \\
\mathrm{t}(9 ; 22)(\mathrm{q} 34 ; \mathrm{q} 11.2),-15, \operatorname{der}(22) \mathrm{t}(9 ; 22)(\mathrm{q} 34 ; \mathrm{q} 11.2) \\
\mathrm{t}(15 ; 22)(\mathrm{q} 23 ; \mathrm{q} 11.2)[\mathrm{cp} 9] \\
\bullet / / 46, \mathrm{XY}[11]\end{array}$ & $\begin{array}{l}\text { - XX (56\%), del(5)(q31) (1\%) } \\
\text { - } \mathrm{BCR} / \mathrm{ABL} 1(22.5 \%) \\
\text { - } \operatorname{der}(22) \mathrm{t}(15 ; 22)(\mathrm{q} 23 ; \mathrm{q} 11)(100 \%) \\
\text { - } \mathrm{XY}(44 \%)\end{array}$ \\
\hline$\# 9$ & $1 / 27 / 16$ & $\mathrm{BM}$ & $\begin{array}{l}\bullet 45 \sim 46, X X, \operatorname{der}(5) \mathrm{t}(5 ; ?)(\mathrm{p} 15 ; ?), \mathrm{t}(9 ; 22) \\
(\mathrm{q} 34 ; \mathrm{q} 11.2), 15, \operatorname{der}(22) \mathrm{t}(9 ; 22)(\mathrm{q} 34 ; \mathrm{q} 11.2) \mathrm{t}(15 ; 22) \\
(\mathrm{q} 23 ; \mathrm{q} 11.2)[\mathrm{cp} 2] \\
/ 46, \mathrm{XX}[14] \\
\bullet / / 46, X Y[4]\end{array}$ & $\begin{array}{l}\text { - XX }(69 \%), \operatorname{del}(5)(q 31)(1.5 \%) \\
\text { - BCR/ABL1 }(1.5 \%) \\
\text { • XY }(30.5 \%) \\
\text { Normal } 8(100 \%)\end{array}$ \\
\hline
\end{tabular}

${ }^{\star} \#$ - Number; ${ }^{* \star B M}$ - Bone Marrow; ${ }^{* * *} \%+$ - Percent Positive; ${ }^{* * *}$ UB - Unstimulated Blood

- - Patient karyotype and FISH; ••- Donor karyotype and FISH 
Zaslav et al. Hematology and Leukemia 2016,

http://www.hoajonline.com/journals/pdf/2052-434X-4-2.pdf

Table 2. Hematology results.

\begin{tabular}{lllll}
\hline Date & White Blood Cells $(\mathbf{k} / \boldsymbol{\mu L})$ & Hemoglobin $(\mathbf{g} / \mathbf{d L})$ & Platelets $(\mathbf{k} / \mu \mathrm{L})$ & Blast $(\%)$ \\
\hline $8 / 5 / 2010$ & 4.2 & 11.9 & 271 & 2.0 \\
$7 / 18 / 2014$ & 93.8 & 8.3 & 887 & 14.0 \\
$7 / 25 / 2014$ & 47.4 & 7.2 & 1232 & 8.0 \\
$7 / 29 / 2014$ & 59.39 & 7.2 & 1416 & 5.0 \\
$11 / 14 / 2014$ & CBC not performed & CBC not performed & CBC not performed & CBC not performed \\
$4 / 24 / 2015$ & CBC not performed & CBC not performed & CBC not performed & CBC not performed \\
$7 / 22 / 2015$ & 1.32 & 10.2 & 137 & 0.0 \\
$11 / 16 / 2015$ & CBC not performed & CBC not performed & CBC not performed & CBC not performed \\
$12 / 02 / 2015$ & 10.21 & 3.12 & 294 & 0.0 \\
$01 / 27 / 2016$ & 2.95 & 3.57 & 11 & 0.0 \\
\hline
\end{tabular}

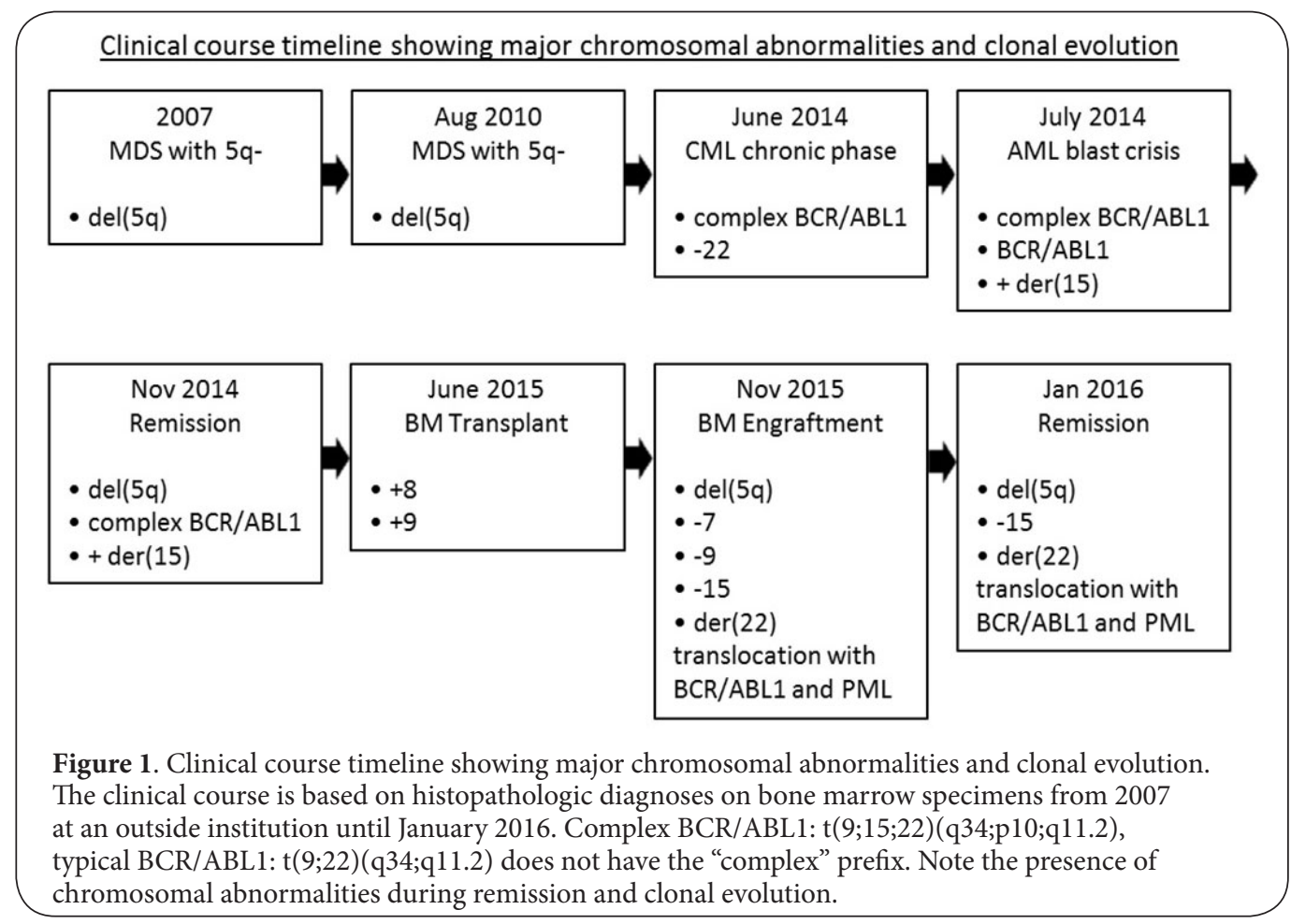

blood (UB). Analyses were performed nine different times. G-banding was performed on 15 to 20 metaphase cells per analyses. FISH analysis was performed on 200 nuclei and/or 10 metaphase cells.

FISH probes: LSI 5q EGR1/D5S23 (5q31/5p15.2), LSI CEP8 (8p11.1-q11.1)(D8Z2), LSI BCR/ABL1 DFDC (22q11/9q34) and LSI SNRPN (15q11.2,CEP15,PML[15q22-q24]). (All probes were supplied by Abbott Molecular, Des Plaines, IL, USA). Flow cytometry was performed using a Becton Dickinson FACSCalibur using BD anti-CD33 (340679) and anti-CD34 (340667). Blood counts were performed using a Sysmex XN-10. $B C R / A B L 1$ (p210) fusion transcript was quantified by RT-qPCR utilizing the Xpert BCR-ABL monitor kit, Cepheid, San Jose,
CA. RNA was extracted from the patient's peripheral blood with the QIAamp RNA blood minikit, Qiagen, Germany. The RNA was reverse transcribed and then amplified by realtime$P C R$ with the Light-Cycler. BCR/ABL1 was quantified by using the $t(9 ; 22)$ quantification kit from Roche Molecular Systems Inc, Branchburg, NJ (this kit does not distinguish between p210 and p190).

\section{Results}

In 2007, the patient presented with MDS with 5q-syndrome at an outside institution. In August 2010 at our institution, morphologic evaluation of the BM was consistent with MDS and G-banded chromosome analysis revealed a deletion of 
Zaslav et al. Hematology and Leukemia 2016,

http://www.hoajonline.com/journals/pdf/2052-434X-4-2.pdf

doi: 10.7243/2052-434X-4-2

part of the long arm of chromosome 5 [i.e., del(5)(q12q33)] in $11 / 20$ metaphase cells and confirmed by FISH (all cytogenetic results are summarized in Table 1 ).

In June 2014, bone marrow biopsy showed a hypercellular marrow with left-shifted granulocytic and megakaryocytic hyperplasia, consistent with transformation to $\mathrm{CML}$ in chronic phase (Figure 2). Cytogenetic and FISH analyses of the BM revealed the del( $5 q)$ in $1.5 \%$ of nuclei and a complex BCR/ $A B L 1$ translocation: $45, X X, t(9 ; 15 ; 22)(q 34 ; p 10 ; q 11.2),-22$ in all metaphase FISH cells (Figure 3, Table 1).

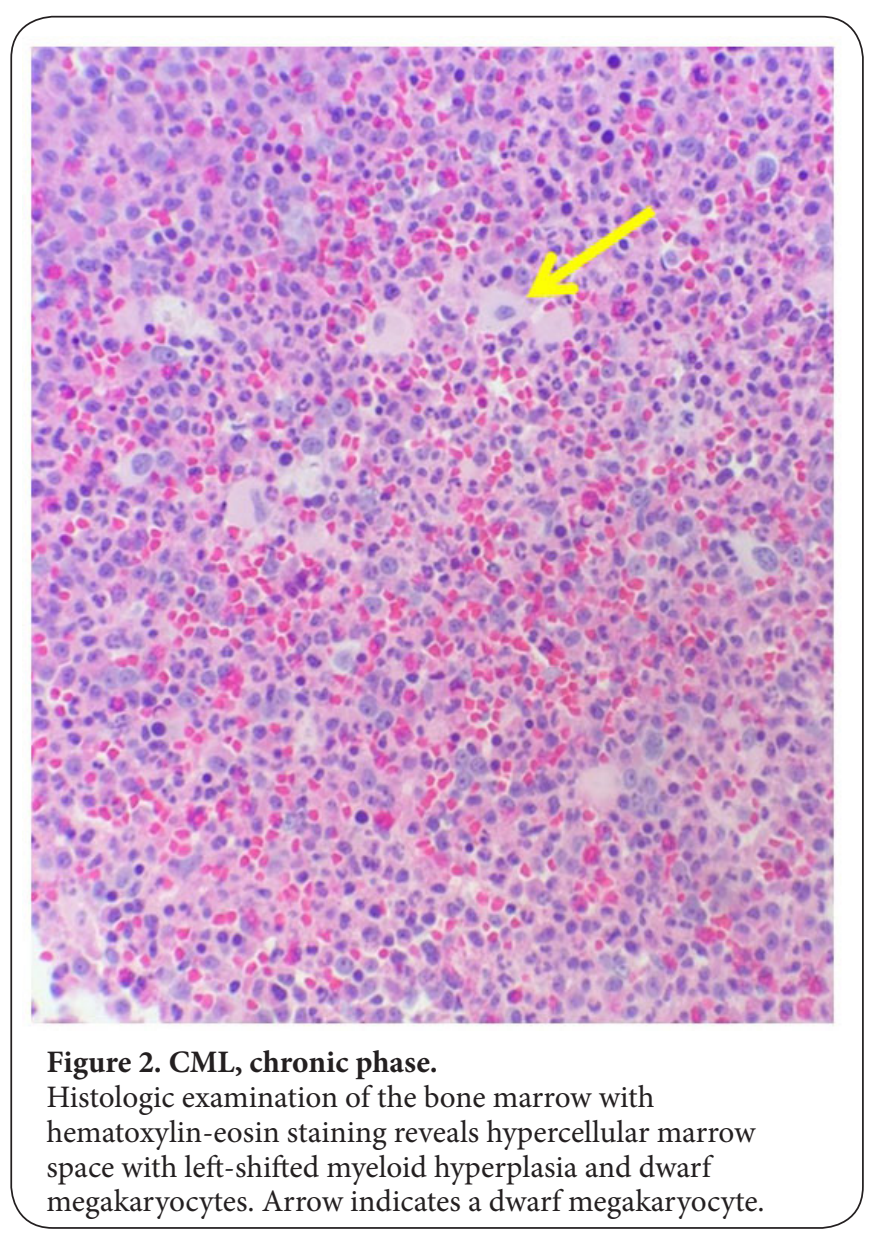

Seven weeks later in July 2014, she was in blast crisis with $14 \%$ blasts in the peripheral blood (PB) and $18 \%$ blasts by flow cytometry of the BM. G-banding and FISH of unstimulated blood (UB) revealed both the complex translocation and further clonal evolution. An additional $\operatorname{der}(15) \mathrm{t}(9 ; 15 ; 22)$ (q34;p10;q11.2) in 5/20 metaphase cells was observed. RT-PCR molecular testing showed a p210 BCR/ABL1 transcript level of $>10 \%$ (Table 3 ). The del( $5 q$ ) was not present in this analysis. The patient transformed from CML to myeloid blast crisis in less than a month.

Twelve weeks later in November 2014, cytogenetic and FISH analysis of the remission BM revealed the same clones

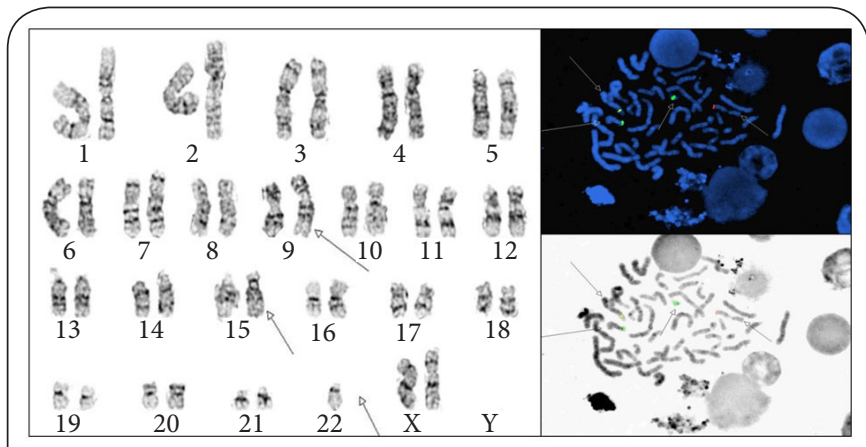

Figure 3. G-banded metaphase from analysis \#2: $45, X X, t(9 ; 15 ; 22)(q 34 ; p 10 ; q 11.2),-22$.

Arrows indicate the derivative chromosomes (left panel). FISH-DAPI (top right panel) and Reverse-DAPI (bottom right panel), where arrows indicate the normal chromosome 9 (red), normal chromosome 22 (green), der(9) (yellow), and der(15) (yellow).

Table 3. BCR/ABL1 transcript results.

\begin{tabular}{llll}
\hline Specimen & Date & BCR/ABL1p210 & $\begin{array}{l}\text { BCR/ABL1p210 } \\
\text { and p190 }\end{array}$ \\
\hline blood & $7 / 15 / 2014$ & $>10 \%$ & -- \\
blood & $8 / 12 / 2015$ & -- & not detected \\
blood & $12 / 11 / 2015$ & $>10 \%$ & -- \\
blood & $12 / 21 / 2015$ & $>10 \%$ & -- \\
blood & $1 / 12 / 2016$ & $>10 \%$ & -- \\
blood & $1 / 23 / 2016$ & $1.8 \%$ & -- \\
\hline
\end{tabular}

present in July 2014 and the del(5q) in 1/20 metaphase cells and in $1 / 200$ nuclei of FISH analyses. In addition to the del(5q), a $\operatorname{der}(15) t(9 ; 15 ; 22)(q 34 ; p 10 ; 11.2)$ was present in $8 / 20$ metaphase cells and a der(22)t(9;22)(q34;q11.2) was present in $1 / 20$ metaphase cells.

Twenty-one weeks later in April 2015, nuclear FISH of PB revealed del $(5 q)$ in $1 / 200$ nuclei, a variant $B C R / A B L 1$ translocation in 6/200 nuclei, and three copies of ABL1 [i.e., trisomy 9] in $32 / 200$ nuclei.

In June 2015, the patient had a haploidentical allogeneic bone marrow transplant from her son. The bone marrow biopsy at the end of June 2015 showed normal marrow morphology, cellularity and normal flow cytometry findings proving she was in morphologic and immunophenotypic remission. However, chromosome analysis and FISH of the BM showed +8 in 10/200 nuclei and +9 in 12/200 nuclei. The variant BCR/ $A B L 1$ and del(5q) were not detected.

In November 2015, post-transplant evaluation of the BM revealed normal marrow morphology and cellularity, normal blood counts, and normal flow cytometry. Cytogenetic and FISH analyses revealed a mixture of male and female cells. All of the female cells were abnormal [i.e., 42 46,XX,der(5) $\mathrm{t}(5 ; ?),-7,-9, \mathrm{t}(9 ; 22)(\mathrm{q} 34 ; \mathrm{q} 11.2),-15, \operatorname{der}(22) \mathrm{t}(9 ; 22)(\mathrm{q} 34 ; \mathrm{q} 11.2)$ $\mathrm{t}(15 ; 22)(\mathrm{q} 23 ; \mathrm{q} 11.2)[\mathrm{cp} 9]$. In this clone, the der(22) had BCR/ 
$A B L 1$ translocated to the long arm of the der(22) and PML (15q23) translocated to the short arm of the der(22) (Figure 4). FISH showed the reappearance of the BCR/ABL1 translocation in $45 / 200$ nuclei and del(5q) in 2/200 nuclei. FISH also showed a normal signal pattern for chromosome 8. RT-PCR molecular testing for the p210 BCR/ABL1 transcript was positive $>10 \%$ (Table 3).

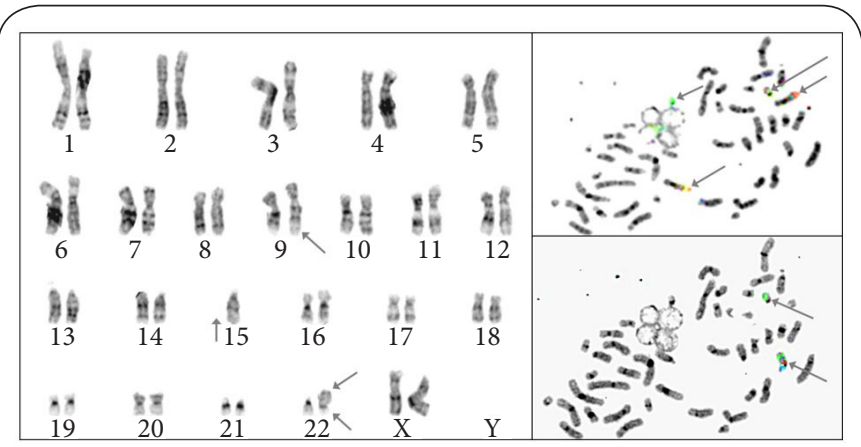

Figure 4. G-banded metaphase from analysis \#8:

$45, \mathrm{XX}, \operatorname{der}(5) \mathrm{t}(5 ; ?), \mathrm{t}(9 ; 22)(\mathrm{q} 34 ; \mathrm{q} 11.2),-15, \operatorname{der}(22) \mathrm{t}(9 ; 22)$

$(\mathrm{q} 34 ; \mathrm{q} 11.2) \mathrm{t}(15 ; 22)(\mathrm{q} 23 ; \mathrm{q} 11)$.

The der(22) has BCR/ABL1 translocated to the long arm of the der(22) and PML (15q23) translocated to the short arm of the der(22). The arrows indicate the derivative chromosomes 9 and 22 and the missing chromosome 15 homolog (left panel). Top right panel reverse-DAPI image demonstrates the BCR/ABL1 translocation on the long arm of the $\operatorname{der}(22)$. Arrows indicate the normal chromosome 9 (red), the normal chromosome 22 (green), the $\operatorname{der}(9)$ (yellow) and the $\operatorname{der}(22)$ (yellow). Bottom right panel reverse-DAPI image demonstrates PML (15q23) (green) on the short arm of the der(22). Arrows indicate the normal chromosome 15 and the $\operatorname{der}(22)$.

In December 2015, she developed a rash and was diagnosed with Graft-versus-Host Disease (GVHD) treated with photophoresis. Her most recent bone marrow biopsy from January 2016 showed trilineage engraftment and no morphologic and no immunophenotypic evidence of MDS, AML, or CML. However, BCR/ABL1 was present in the chromosomes FISH and by RT-PCR (Tables 1 and 3, Figure 4).

\section{Discussion}

The transformation from MDS to CML has rarely been reported [6]. To our knowledge, this is the first report of rapid progression to $\mathrm{CML}$ myeloid blast crisis with a complex BCR/ABL1 translocation $[45, \mathrm{XX}, \mathrm{t}(9 ; 15 ; 22)(\mathrm{q} 34 ; \mathrm{p} 10 ; \mathrm{q} 11.2),-22]$ (Figure 1) in this clinical scenario. The patient had clonal cytogenetic evolution with chromosomal gains and losses of diverse cell populations during the various phases of therapy and during remission.

AML has been proposed to arise from Class I and Class II mutations. Class I mutations increase cell proliferation and survival, whereas Class II mutations suppress differentiation and apoptosis. BCR/ABL1 is a Class II mutation that impairs differentiation and apoptosis [3]. In AML, cooperation of Class
II mutations suppressing differentiation with Class I mutations increasing cell proliferation are frequently seen with $B C R / A B L 1$ positive subclones in patients with AML. This was reported in a small series of patients by Bacher et. al., 2011 [4]. These subclones occurred in various subtypes of $A M L$ and one patient had del $(5 q)$. It is possible that the BCR/ABL1 translocation could cooperate with different mutation types in $\mathrm{AML}$ as a Class I mutation promoting cell proliferation of the abnormal clones. As the BCR/ABL1 translocation only occurs in approximately $1 \%$ of patients with AML [5], this may be significant for cell proliferation.

Fukunaga [6] reported a case of MDS that initially presented with del( $5 q)$ and add $(16 q)$. After 18 months, the patient still had the del $(5 q)$, add $(16 q)$ clone, but also acquired a $t(9 ; 22)$ (q34;q11.2), an add(1)(q32), and a +8 clone. Our patient also acquired the complex BCR/ABL1 translocation and $a+8$ clone. After the appearance of the $t(9 ; 22)(q 34 ; q 11.2)$, the BM in both cases showed AML morphology.

The BCR/ABL1 translocation occurs in $<1 \%$ of MDS patients [5]. The few reported cases support evidence that the process represents multistep leukemogenesis. The initial event may result from clonal proliferation of stem cells in the acquisition of the translocation existing in neoplastic cells [6]. Some patients with AML may acquire the translocation as an additional chromosome abnormality during the evolution of the disease or during relapse, as reported by Bacher [4] and seen in our patient. Three possible explanations for the late appearing $\mathrm{BCR} / \mathrm{ABL} 1$ translocation are:

1. It may have been present during the course of the patients' disease, but the patient was not cytogenetically evaluated for four years.

2. It may represent evidence of a multistep process.

3. The translocation may represent a new clone in leukemic relapse [6-9].

These findings indicate that the translocation could have arisen during various times within the overall course of the disease. The patient went from MDS to CML to an AML-like blast crisis within one month. To our knowledge, this was the first report associated with this complex BCR/ABL1 translocation: $45, X X, t(9 ; 15 ; 22)(q 34 ; p 10 ; q 11.2)$,-22 with rapid progression resulting in the loss and gain of diverse cell populations. This case illustrated the importance of careful patient monitoring to diagnose the nature of this disease and to accordingly modify the course of treatment. Additional cases of MDS with complex BCR/ABL1 translocations are needed to further determine the clinical significance of these findings.

\section{Competing interests}

The authors declare that they have no competing interests.

\section{Publication history}

Editors: Pedro C. Redondo, University of Extremadura, Spain.

Tarek M. A. Owaidah, Al Faisal University, Saudi Arabia.

Received: 04-Apr-2016 Final Revised: 09-May-2016

Accepted: 23-May-2016 Published: 02-Jun-2016 


\section{Authors' contributions}

\begin{tabular}{|l|c|c|c|c|c|c|c|c|c|c|c|c|c|}
\hline Authors' contributions & ALZ & RG & BB & MS & BJ & EK & DT & PF & TM & SS & MG & YM & TA \\
\hline Research concept and design & $\checkmark$ & -- & -- & -- & -- & -- & -- & -- & -- & -- & -- & -- & $\checkmark$ \\
\hline Collection and/or assembly of data & $\checkmark$ & $\checkmark$ & $\checkmark$ & $\checkmark$ & $\checkmark$ & $\checkmark$ & $\checkmark$ & $\checkmark$ & -- & $\checkmark$ & $\checkmark$ & $\checkmark$ & $\checkmark$ \\
\hline Data analysis and interpretation & $\checkmark$ & $\checkmark$ & $\checkmark$ & $\checkmark$ & $\checkmark$ & $\checkmark$ & $\checkmark$ & $\checkmark$ & $\checkmark$ & $\checkmark$ & $\checkmark$ & $\checkmark$ & $\checkmark$ \\
\hline Writing the article & $\checkmark$ & -- & -- & -- & -- & -- & -- & -- & -- & -- & -- & -- & $\checkmark$ \\
\hline Critical revision of the article & $\checkmark$ & $\checkmark$ & -- & -- & -- & -- & -- & -- & -- & -- & -- & -- & $\checkmark$ \\
\hline Final approval of article & $\checkmark$ & -- & -- & -- & -- & -- & -- & -- & -- & -- & -- & $\checkmark$ & $\checkmark$ \\
\hline Statistical analysis & $\checkmark$ & $\checkmark$ & -- & -- & -- & -- & -- & -- & -- & -- & -- & -- & $\checkmark$ \\
\hline
\end{tabular}

\section{References}

1. McPherson R and Pincus M. Henry's clinical diagnosis and management by laboratory methods. Philadelphia, PA: Elsevier Saunders.

2. Campo E, Swerdlow SH, Harris NL, Pileri S, Stein H and Jaffe ES. The 2008 WHO classification of lymphoid neoplasms and beyond: evolving concepts and practical applications. Blood. 2011; 117:5019-32. | Article | PubMed Abstract | PubMed FullText

3. Specht A, Bernard P, Goeldner M and Peng L. Mutually induced formation of host-guest complexes between p-sulfonated calix[8]arene and photolabile cholinergic ligands. Angew Chem Int Ed Engl. 2002; 114:4900-4902. | Article | PubMed

4. Bacher $U$, Haferlach T, Alpermann T, Zenger M, Hochhaus A, Beelen DW, Uppenkamp M, Rummel M, Kern W, Schnittger S and Haferlach C. Subclones with the $t(9 ; 22) / B C R-A B L 1$ rearrangement occur in AML and seem to cooperate with distinct genetic alterations. Br J Haematol. 2011; 152:713-20. | Article | PubMed

5. Keung YK, Beaty M, Powell BL, Molnar I, Buss D and Pettenati M. Philadelphia chromosome positive myelodysplastic syndrome and acute myeloid leukemia-retrospective study and review of literature. Leuk Res. 2004; 28:579-86. | Article | PubMed

6. Fukunaga A, Sakoda H, Iwamoto Y, Inano S, Sueki Y, Yanagida S and Arima N. Abrupt evolution of Philadelphia chromosome-positive acute myeloid leukemia in myelodysplastic syndrome. Eur J Haematol. 2012; 90:245-9. I Article | PubMed

7. Gilliland DG. Hematologic malignancies. Curr Opin Hematol. 2001; 8:18991. I PubMed

8. Ebert BL, Pretz J, Bosco J, Chang CY, Tamayo P, Galili N, Raza A, Root DE, Attar E, Ellis SR and Golub TR. Identification of RPS14 as a 5q- syndrome gene by RNA interference screen. Nature. 2008; 451:335-9. | Article | PubMed Abstract | PubMed FullText

9. Jacobsen RJet. al. Late appearance of Philadelphia Chromosome. British Journal of Haematology. 2008; 63:392-394.

\section{Citation:}

Zaslav A-L, Gupta R, Burks BT, Schuster M, Jalilizeinali B, Knorr E, Tully D, Fernicola P, Mercado T, Spitzer S, Golightly M, Ma Y and Ahmed T. Transformation of myelodysplastic syndrome with isolated $5 q$-syndrome to chronic myelogenous leukemia with a novel complex $\mathrm{BCR} / \mathrm{ABL} 1$ translocation with rapid progression to blast crisis. Hematol Leuk. 2016; 4:2.

http://dx.doi.org/10.7243/2052-434X-4-2 